\title{
Reflections of a CSL Groupie
}

\author{
Jane Hennig
}

\begin{abstract}
The Volunteer Action Centre has been an active supporter of community service-learning and other forms or community-engaged scholarship in partnership with three large post-secondary institutions in Waterloo Region. Over the years, staff have connected with local and national projects to enhance our understanding of engaged scholarship and try to translate that knowledge to benefit our community. This article explores the personal reflections of a community partner/broker. The author has a high level of respect for the institutions that connect their students, faculty, and staff with the community of which they are a part, but also has experienced some of the challenges of bureaucracy. This reflection attempts to share some of the ground-breaking work of local community-post-secondary partnerships while acknowledging some of the very real challenges of this kind of shared work.
\end{abstract}

KEYWORDS broker; McConnell Ten; multi-institutional; C2U

Over the years, I have been asked to participate in community service-learning (CSL) as a broker, a researcher, a spokesperson, and an advisor. I have advocated for service-learning as an important component of community-post-secondary relationships. As the Executive Director of the Volunteer Action Centre of Kitchener Waterloo \& Area for fourteen years, ${ }^{1}$ I have engaged in the work of CSL and other community-engaged scholarship (CES) at both a local and national level. This essay brings together a history of my personal involvement with CSL and my reflections about its role in the larger relationship between post-secondary institutions and the communities of which they are a part. ${ }^{2}$

It has been an incredible journey that began out of necessity in 2003. The staff at our Centre and the community organizations we work with were experiencing a dramatic increase in the number of students or instructors that would call each September and January looking for places in the community where they could offer student skills. Sometimes the projects they had in mind were for small teams, sometimes they were for larger groups, but mainly they were

\footnotetext{
${ }^{1}$ Volunteer centres work in local communities to strengthen volunteering and citizen engagement. Though diverse in many ways, they share the following common functions: to promote volunteering; to build the capacity of organizations to engage volunteers; to facilitate connections between people with volunteer opportunities; and to provide leadership on issues related to volunteering and citizen engagement. All of this aligns the work of volunteer centres directly with the intended outcomes of community service-learning.

${ }^{2}$ It is hard to write personal memories without sharing specific names and roles. The people and roles named are those for whom I hold high regard. These individuals have had a positive influence on CSL locally and nationally and should be acknowledged for the impact that they have made. I hope that I represent them well.
} 
for individuals, and usually for two hours per week for ten weeks. ${ }^{3}$ The board and staff of our Centre determined that our best opportunity to manage this growing phenomenon was to get more closely involved. Our first step was to seek out key connections at each post-secondary institution in our community. My formal relationship with CES was to begin locally, grow to national participation, and, of late, has moved back to focusing on my own community. I have learned a great deal about campus-community engagement and continue to value and advocate for it.

In 2005, our Centre supported the successful application that saw Wilfrid Laurier University become one of the "McConnell Ten." Wilfrid Laurier had been engaged in CSL for nearly forty years; it was just not defined as such. Laurier professors and students had a positive relationship with community organizations through placements and research projects that were tied to curriculum before my tenure at the Volunteer Action Centre. Many of the organizations that we worked with were already connecting with instructors and some relationships were as longstanding as the organizations themselves. Now, with funding, it became an intentional institutional direction. This felt like a natural progression in some ways, yet the growth in interest from the post-secondary institutions also felt daunting for organizations who were considering how to grow opportunities at a similar rate.

The volunteer centre went on to be active in helping to facilitate connections for the Laurier Centre for Community Service-Learning (LCCSL), and we participated on a community advisory for LCCSL. Its Director was very open to exploring new approaches as long as they continued to meet the participation numbers and reporting requirements. This meant continuous growth in the numbers of students active in a community setting. It is important to note that we are situated in a community with a population of approximately 500,000 , where the student body exceeds 60,000. While LCCSL focused its efforts on growing CSL for its institution, the University of Waterloo and Conestoga College were also implementing and growing CSL courses for students. Community organizations were beginning to feel stretched.

In 2007, Cheryl Rose, then Executive Director of the Canadian Alliance for Community Service-Learning (CACSL), and John Cawley, then Senior Program Officer from the McConnell Foundation, invited me, with about thirty other community participants from across Canada, to meet in Toronto to discuss the CSL experience from a community perspective. It was fascinating to hear what other community members were experiencing. We had much in common: excellent opportunities, real challenges, and almost unanimously the experience that "community" was an afterthought in CSL. One outcome of that meeting was a letter to the McConnell Ten that clearly set out the need for CSL programs to be more considerate of their community partners (Cawley, 2007).

At this point, Paul Davock, then Director of LCCSL, began to focus on new approaches to the Laurier program, even if it meant slowing the growth in participation numbers. I commend this approach because it really positioned community as the priority for the first time. The

\footnotetext{
${ }^{3}$ Twenty hours per term (two hours per week) remains a common number of hours for service-learning placements.

${ }^{4}$ See Kahlke and Taylor, this issue, for more on the J.W. McConnell Foundation's funding of CSL initiatives at ten institutions in Canada.
}

Engaged Scholar Journal: Community-Engaged Research, Teaching and Learning 
steering committee for the Centre, which involved faculty, community, and students, began to explore new strategies to support community. From this, the Volunteer Action Centre began to facilitate a multi-institutional committee to evaluate service-learning and explore if and how we could develop a community-wide approach to service-learning in our Region. It was an incredibly proactive approach; at the table were three major post-secondary institutions, local funders, students, and community organization representatives.

This multi-institutional committee simultaneously took a what we called a "macro" and "micro" approach to our work. The macro working group looked at the institutional approach to CSL, delving into the three major post-secondary institutions in our community in terms of liability, risk management, overall participation and expectations, and forms of CSL (e.g. curricular or co-curricular). From an outsider's perspective, it was interesting to learn that, to find out what CES was taking place in our community, we needed to undertake ethics reviews in order to ask each department which instructors or which courses were engaged in CSL and how it was being done. To ask what we presumed was a simple question for internal use, we were required to go through not one but three ethics reviews that had to be accepted by three different review panels in three different post-secondary institutions. This is in contrast to experiences in even the largest of community organizations: when we want to ask an internal question and gauge what our departments are doing, we just ask the question and get the response. In this case, we were looking at ways to be more strategic about CSL and community-based research (CBR) to ensure a benefit to all stakeholders, but we experienced many bureaucratic road blocks.

Paralleling the macro work was a micro working group that looked at options for CSL programming. It met with community organization staff to explore alternatives and create CSL projects. Because the group was cross-institutional, there was a focus on a more balanced approach to CSL that, in my opinion, was the best approach to campus-community work that I have seen. Unlike many CSL projects, which are often determined by only one or two stakeholders, the micro group brought together faculty, students, and volunteer managers to develop projects that would add value to all participants. After three and a half years, however, staff changes at all three post-secondary institutions led to the breakdown of this model. Without three equally strong champions at each post-secondary institution, the process ceased. In my opinion, there was so much more that could have been accomplished with this macro approach.

When LCCSL undertook an extensive evaluation process in 2010, then LCCSL Director, Kate Connolly, asked me to be a research assistant for the process. She felt strongly that having a community partner on the research team, and not only as a survey or focus group participant, would add value and credibility to the project. Dr. Terry Mitchell was the lead investigator and welcomed the unique process. I found the process, the research, and the writing to be great experiences. I also found that, even though I have a Master of Arts degree from Wilfrid Laurier University and certification as a facilitator, my participation in the research as a seasoned veteran in our community sector was still new to some participants. While the participants from community and my fellow researchers accepted me in the research role, 
many of the on-campus participants struggled to accept an outsider as part of the research team. In an age where knowledge mobilization is a focus for post-secondary institutions, an approach that actually respected the knowledge and expertise of a non-academic was (and in many ways still is) new and not always welcomed.

In 2008, I joined the Advisory Board for the Canadian Alliance for Community ServiceLearning (CACSL). Being involved with CACSL was a great opportunity for me to learn about what was happening in CSL in other parts of Canada. I was introduced to faculty and service-learning administrators from across the country, but initially there were very few community members at the table. At the CACSL Symposium in Ottawa in 2010, there were, I believe, only two community representatives. Imagine my chagrin when I was asked to come to the microphone and speak "for the nonprofit sector"; there were, at the time, approximately 165,000 nonprofits with nearly one million paid employees in Canada, and I was a staff member at one of them. There was no way that I could speak for, or represent, an entire sector. This moment certainly speaks to a lack of engagement of community at such an event. And while each year there has been better interaction between community and postsecondary constituents, there is still a massive divide between these groups when it comes to learning together.

The intentional inclusion of Colleges in the $\mathrm{C}^{2} \mathrm{U}$ (Community/College/ University) Expo and the efforts of CACSL to partner with Volunteer Centres at the alliance's semi-annual conference have increased opportunities for community members to participate in conferences and knowledge sharing with post-secondary institutions. These conferences are opening lines of communication and bringing community and faculty together in an environment away from the classroom. Yet there is still a divide. Most academics choose to attend sessions that are centered on post-secondary concerns. The joint sessions and community sessions have the lowest attendance. The keynotes tend to speak to the academic audience and, often, do not seem aware that there is other representation at the sessions.

I am thrilled to see more inclusion of community with post-secondary faculty in the joint learning environment offered by these conferences. I am, however, not convinced that we yet have a forum that will drive the change needed for CSL and CBR. I hope that there may be an opportunity to create such a forum with the recent change from CURA (Community-University Research Alliances) funding to the new Partnership Grant funding model through the Social Sciences and Humanities Research Council (SSHRC). As I understand it, the intention of the new model is to be more inclusive and more equal in the funding and infrastructure aspects of partnerships related to these grants. As a past member of the steering committee for the Community First: Impacts of Community Engagement (CFICE) project, a SSHRC Partnership-funded initiative, I see the influence that a truly inclusive steering committee (including community representatives as well as academics) can have on a national project.

There is much value to be found in having good relationships with post-secondary institutions. First and foremost is the opportunity to engage young people in community programs and services. Studies demonstrate that if you engage individuals while they are still young, they are more likely to become life-long volunteers (Lyons, 2013). In effect, as

Engaged Scholar Journal: Community-Engaged Research, Teaching and Learning 
members of community organizations, we are helping to raise a new generation of engaged and contributing citizens. So, our primary focus is the future. But in terms of the present, we see CSL as an opportunity to provide students with experience that matches the theory they are learning at school. Many of these young people will be applying to work in the non-profit sector in the future, and adding a practical application component to their education is helpful for future hires. Finally, we see the relationship as one that opens doors to faculty and staff involvement, allowing us to access skill sets that we might not be able to tap otherwise.

In my over ten years of being connected to service-learning in Canada, I have been passionate about the potential of all things campus-community. It is that passion for the potential that keeps me connected to and a true advocate for this pedagogy. I have had to step back from my national work with CACSL and CFICE for now, but I continue to work actively with the post-secondary institutions in my region to build campus-community relationships and programs that will truly benefit the people we all serve.

\section{About the Author}

Jane Hennig is the Executive Director of the Volunteer Action Centre, which provides services that strengthen the capacity of over 160 charity and not-for-profit organizations to engage and support volunteerism in Waterloo Region. Jane currently provides sector leadership through her work on the Board of Directors for Volunteer Canada and on committees for Wellbeing Waterloo Region and the City of Waterloo Neighbourhood Strategy. She is an active participant in the Ontario Volunteer Centre Network and continuously works to demonstrate the value of community engagement locally and beyond. While her national work related to Community Service Learning has stepped back, she and her staff continue to work closely with faculty and staff at Conestoga College, University of Waterloo and Wilfrid Laurier University. Email: jane@volunteerkw.ca

\section{References}

Cawley, J. (2007, September 14). Dear Cheryl [letter to Cheryl Rose].

Lyons, L. (2013). Characteristics of 4-H participants and their psychosocial development (Master's thesis). Utah State University, Logan, UT. 